DOI: 10.20472/IAC.2019.051.039

\author{
PHANTHIPA SRINAMMUANG \\ Faculty of Business Administration, Kasetsart University, Thailand \\ NADHAKAN SHINNARANANTANA \\ Faculty of Business Administration, KASETSART UNIVERSITY, Thailand
}

\title{
THE SIGNIFICANCE OF FORENSIC ACCOUNTING IN FRAUD: A CASE OF XYZ UNIVERSITY, THAILAND
}

\begin{abstract}
:
This study investigated the Accounting fraud of XYZ University, Thailand and examined the significance of forensic accounting base on the scenario of the case and determined the preventive measure that will be useful in the future, and creating a strategy to keep such case from occurring not only in public university but as well as in government institutions. The examination utilized the subjective research by mulling over the announcement of official statement circulated in Television and newspaper. The examination discovered that the forensic accounting application both $X Y Z$ University and $A B C$ Bank rehearsed poor interior control framework. The case of XYZ University demonstrated the insufficiency of present philosophies of inner and outside controls and auditing framework, thus we recommended the following: real-time checking, initiate periodical investigations, recording systems and arraignment, and separate accounting tasks. Also, we suggested to develop forensic accounting in the organization, especially the personnel involve in the finances of the company and awareness of fraud triangle.
\end{abstract}

\section{Keywords:}

fraud, fraud triangle, pressure, opportunity, rationalization, and forensic accounting

JEL Classification: M40 